\title{
Economic Valuation of Grazing Management Practices: Discrete Choice Modeling in Pastoral Systems of Kenya
}

\author{
Alphayo I. Lutta ${ }^{1}$, Lance W. Robinson ${ }^{3}$, Eric Ruto ${ }^{2}$, Oliver V. Wasonga ${ }^{1}$, Jason \\ Sircely $^{3}$, Moses M. Nyangito ${ }^{1}$
}

${ }^{1}$ Department of Land Resource Management and Agricultural Technology, Faculty of Agriculture, University of Nairobi, P.O. Box 29053-00625 Nairobi, Kenya

${ }^{2}$ Lincoln International Business School, University of Lincoln, Lincoln, LN6 7TS, UK

${ }^{3}$ Sustainable Livestock Systems, International Livestock Research Institute

*Corresponding author: Alphayo I Lutta, Telephone: +254727025924; Email:

alphaluta@yahoo.com.

\begin{abstract}
This study estimates the economic contribution of grazing management practices in pastoral systems by specifically undertaking an economic analysis of pastoralists' preferences for grazing management practices and the economic value pastoralists place on them. The study applied the discrete choice experiment technique using a D-optimal design, a multi-attribute preference elicitation method based on the random utility theory and the characteristics theory of value, to evaluate the economic value of grazing management options practiced by pastoralists in Tana River County of Kenya. The results show that pastoral communities derive positive utility in connected systems that enable reciprocal access to resources in both wet and dry seasons. Pastoralism adapts to spatial-temporal variability of pasture and water through herd mobility, hence the positive utility derived from practices that contribute to availability of adequate water and pasture across the seasons. These findings provide empirical evidence on the social and economic net benefits of rangeland management practices that should be enhanced to promote sustainable management of rangeland resources.
\end{abstract}

Key words: Discrete choice experiment, Economic values, Grazing management, Pastoralism, Welfare values 


\section{Introduction}

Rangelands, primarily comprised of savannas and shrub-lands, are found mainly in arid and semiarid zones, which cover about $41 \%$ of the global landmass (UNCCD, 2006). In Africa rangelands make up to $43 \%$ of the total land surface area. In Kenya, rangelands constitute approximately $80 \%$ of the land mass and support over $70 \%$ of livestock population.

In general, African rangelands are characterized by low, spatially and temporally variable rainfall in addition to hot temperatures, leading to high levels of evapotranspiration. Given the scanty vegetation cover found in most rangelands in Africa, they also experience high run off leading to floods (Mwangi and Dohrn, 2006) especially during heavy storms which make them more susceptible to degradation (Reid et al., 2008).

Despite the climatic limitations, rangelands are important socio-economically and ecologically. They offer a variety of ecosystem goods and services, with direct and indirect economic and social benefits to their inhabitants. Specifically, because these areas support the livelihoods of over $40 \%$ of the world's population (De Jode, 2009), there is growing recognition of their importance in meeting the basic needs of their inhabitants, as well as the global food security (Mortmore et al., 2009). In terms of ecological significance, rangelands provide habitats for wildlife, and as observed by Lund (2007) they also act as water catchments for various river systems. Besides, rangelands are also important areas for storage of about $30 \%$ of world soil carbon (FAO, 2009). This implies that sustained higher levels of investment in the management of semi-arid areas can immeasurably support enhanced productivity and better incomes.

A fundamental transformation in management practices as well as better dissemination of knowledge and improved land-use technologies and access to urban markets have the potential of sustainably enhancing production and livelihoods in these areas. Investments in rangelands have largely focused on enhancing livestock production by increasing forage production. This is because livestock production in arid and semi-arid areas is an important source of household food and income and provides an important avenue for employment especially when proper grazing and rangeland management practices that enhance productivity are put in place (Thornton, 2010).

In order to enhance livestock production and protect rangelands from degradation, various management practices have been put in place to promote sustainable management of rangeland resources world over. Some of these practices have not been able to produce the desired levels of 
productivity and thus have failed to improve the welfare of the pastoral communities or prevent rangelands from deteriorating (Macleod and Brown 2014, Torell et al., 2013).

An important contributing factor to the failures of the range management practices is the paucity of comprehensive information on the socio-economic value of the impacts of these rangeland management practices (Costanza et al., 2016). The management of rangelands requires many decisions that would be facilitated by information on pastoralists' preferences on the features that they would like to be included in a rangeland management plans. This enables assessment of potential acceptability of rangeland management policies (such as investment allocation decisions) and provides insights on some of the issues that may affect their implementation, especially considering differences in production systems and relative resource endowments between pastoralists. Failure to include social and economic nonmarket values in decisionmaking processes may lead to undervaluing the net benefits of rangeland practices that affects allocations of investments in conservation and ultimately leading to their degradation (Kelemen et al., 2014).

This study employed the discrete choice experiment (DCE) method (Louviere, 2001) to investigate pastoralists' preferences for various grazing management options and their economic value. A DCE is a stated preference approach for ex-ante analysis of preferences for goods and services that are not yet in the market and would therefore not be possible to evaluate using revealed preference methods (Scarpa et al 2003). Modeling pastoralists' choices allowed evaluation of how they would trade-off different levels of grazing management attributes, consistent with Lancaster's theory of consumer choice (Lancaster, 1966) which suggests that consumption decisions are determined by the utility that is derived from the attributes of a good, rather than from the good per se.

\section{Methods and Study area}

The study was conducted in the rangeland areas of Tana River County located in north eastern side of Kenya as shown in Figure 1. Tana River County has three sub counties-Bura, Galole and Garsen -inhabited primarily by the Orma, Wardey, and Pokomo ethnic communities. The Ormas and Wardeys are pastoralists, while the Pokomo are agro-pastoralists who have settled along river banks where they undertake small scale subsistence farming (Kipchirchir, 2014). Pastoralists generally migrate seasonally with cattle in search for pasture and water. They derive 
a relatively large share of their livelihood from cattle and other livestock species. In contrast, the agro-pastoralists in Tana River County are sedentary; they keep cattle and other livestock species, besides cultivating various crops, and are fairly commercialized.

Tana River County has arid and semi-arid climatic conditions characterized by a hot and dry climate. Average annual temperatures are about $30^{\circ} \mathrm{C}$ with the highest being $41^{\circ} \mathrm{C}$ around January-March, and the lowest being $20.6^{\circ} \mathrm{C}$ during June-July (Kipchirchir, 2014). Rainfall is low, bimodal, erratic and localized in nature. The total annual rainfall ranges between $220 \mathrm{~mm}$ and $500 \mathrm{~mm}$ with long rains occurring in April and May, while short rains fall in October and November with November being the wettest month (Kipchirchir, 2014).

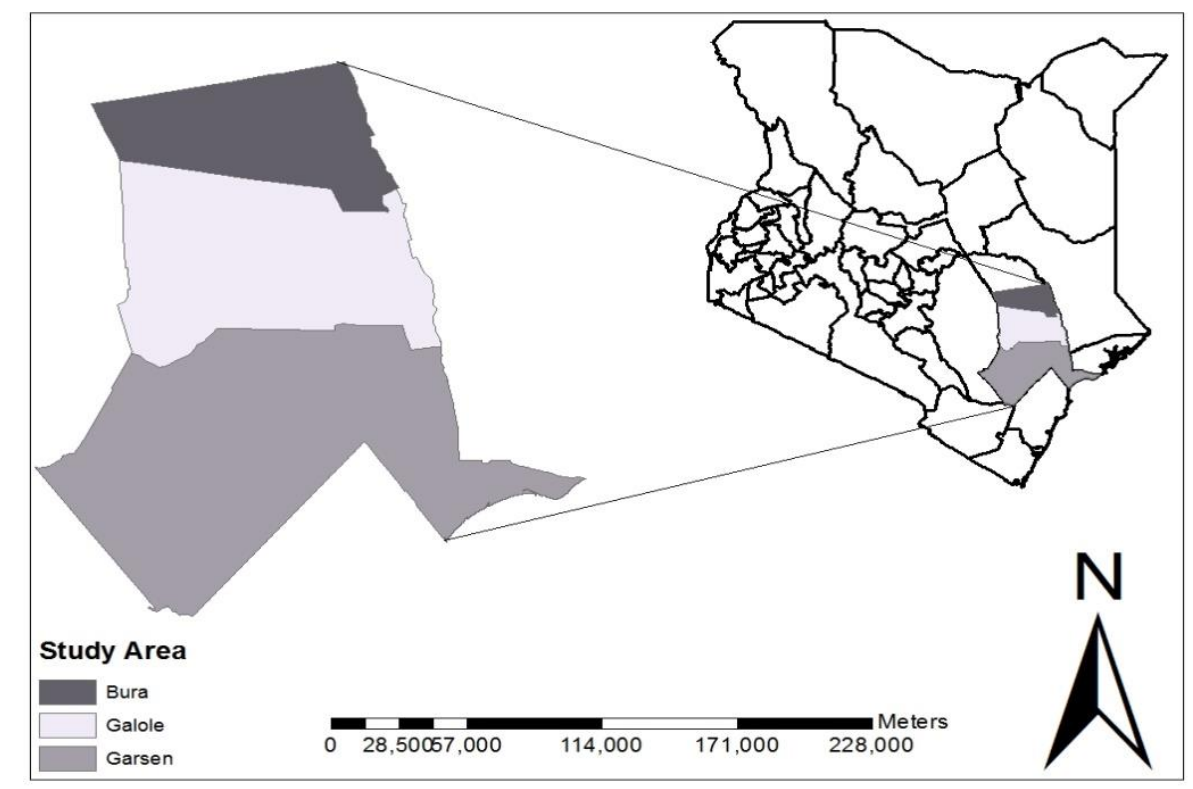

Figure 1: The study Area

\section{Study Design}

This study used discrete choice experiment (DCE) design to determine the economic value of grazing management practices. The use of discrete choice experiment approach has been widely used to determine the economic values of the effects of various environmental interventions (Hanley et al., 2001; Hanley et al., 2006 and Scarpa et al., 2003). Discrete choice experiments are based on stated preferences since they bring about information regarding individuals' preferences of environmental goods and services through the construction of a hypothetical, but 
realistic, market, rather than on preferences of goods and services revealed from the actual behavior of individuals (Ruto et al. 2009). The DCE technique is centered on random utility theory and the characteristics theory of value (Lancaster, 1966), which postulates that preferences for goods are a function of the attributes of the goods rather than the goods themselves. The decision to use a DCE approach for this study was driven by the desire to estimate values for different component parts of grazing management practices. The component parts constitute the attributes in the DCE design. In order to construct the design, grazing management practices were decomposed according to their attributes (or characteristics), and the combination of various levels of this set of attributes resulted in a scenario of change in environmental quality (Otieno 2011).

As required in the construction of the DCE design (Otieno 2011), the most important component attributes of the grazing options/scenarios used in the design of this study were identified by the local community members that included community leaders, government officials of Tana River County and the representatives of water resource user associations through focus group discussions. A total of six focus group discussions (FGD) were conducted to investigate pastoralists' attitudes towards the grazing management practices and to gather background information on what aspects of the grazing scenarios are important to them. The choice of attributes and levels were also based on a combination of evidence from the literature and information from focus group discussions with pastoralists in all the study sites.

According to Scarpa et al. (2003), it is possible to determine the welfare estimates for combination of attribute changes by including price or cost as one of the attributes. This enables estimation of willingness-to-pay for changes in attribute levels (Ruto et al., 2009). Therefore, with the addition to the selected attributes, a monetary attribute (price level) was included in this design to enable the calculation of welfare measures. Currently in each community in the study site where there is a water-pan each household contributes 50 Kenyan shillings which translates to 600 shillings (six US dollars) per annum. The money is meant to pay the personnel guarding the water pan and also ensure that it is well maintained. During the FGDs the members agreed that given the addition of forage yield and more water in the water pans to accommodate all the households in the community they would be more willing to pay an addition of either ten or twenty-five shillings per month. This therefore informed the price levels of 720 and 900 Kenyan shillings per annum respectively in this design. The common attributes for the grazing 
management practices identified in the focus group discussions held in study areas that were used in this design are shown in Table 1.

Table 1 Grazing management attributes used in DCE

\begin{tabular}{|c|c|c|}
\hline Management attribute & Description & Levels \\
\hline $\begin{array}{l}\text { Construction of } \\
\text { additional water pans }\end{array}$ & $\begin{array}{l}\text { Construction of additional water pans in the wet } \\
\text { season grazing areas }\end{array}$ & $\begin{array}{l}\text { No } \\
\text { Yes }\end{array}$ \\
\hline $\begin{array}{l}\text { Forage threshold } \\
\text { below which grazing } \\
\text { is not allowed }\end{array}$ & $\begin{array}{l}\text { The minimum amount of forage below which } \\
\text { grazing is restricted to allow grazed pasture to } \\
\text { regenerate after use. }\end{array}$ & $\begin{array}{l}\text { High threshold } \\
\text { Medium threshold } \\
\text { Low threshold }\end{array}$ \\
\hline $\begin{array}{l}\text { Grazing ban near } \\
\text { water points in wet } \\
\text { season }\end{array}$ & $\begin{array}{l}\text { Grazing ban near permanent water points during the } \\
\text { peak of the wet season to reserve pasture for dry } \\
\text { season grazing }\end{array}$ & $\begin{array}{l}\text { Two months ban } \\
\text { Six months ban }\end{array}$ \\
\hline $\begin{array}{l}\text { Increased forage } \\
\text { production }\end{array}$ & Amount of forage produced & $\begin{array}{l}\text { High forage production } \\
\text { Medium forage } \\
\text { production } \\
\text { Low forage production }\end{array}$ \\
\hline $\begin{array}{l}\text { Increased water } \\
\text { availability }\end{array}$ & $\begin{array}{l}\text { Water availability in the water-pans and more } \\
\text { infiltration into the soil }\end{array}$ & $\begin{array}{l}\text { More water } \\
\text { Less water }\end{array}$ \\
\hline Annual grazing fee & $\begin{array}{l}\text { Annual fee paid by households for membership in } \\
\text { the use of grazing areas }\end{array}$ & $\begin{array}{l}\text { KSh. } 600 \\
\text { KSh. } 720 \\
\text { KSh. } 900\end{array}$ \\
\hline
\end{tabular}

In DCE design, it is generally important to use an experimental design approach that maximizes an efficiency criterion (such as D-efficiency), or equivalently, minimizes an error criterion such as the D-error. A design is said to be D-efficient or D-optimal if it has a sufficiently low D-error or yields data that enable estimation of parameters with low standard errors (Scarpa and Rose, 2008). To increase sampling efficiency, D-optimality was maximized through a two-stage design procedure (Bliemer and Rose, 2010). In the first stage a fractional factorial orthogonal design was used in a preliminary survey of 60 respondents in Galole, Bura and Garsen subcounties of Tana River County to obtain coefficients that were then used to generate an efficient design in the second stage. These prior coefficients were then used in the second stage to generate an efficient design, which had a relatively good level of D-optimality (D-efficiency measure of $82 \%$ ) and a good utility balance (B-estimate of $81 \%$ ), which according to Otieno, (2011) indicates that there was an insignificant likelihood of dominance by any alternative in the choice situations. The final design had 24 paired choice profiles that were randomly blocked into six sets of four choice tasks. 
Each respondent in the study area was randomly assigned to one of the six sets and asked to choose the most preferred option in each choice task. Each choice task had two alternatives (1 and 2) and the baseline or status quo (3) as shown in Table 2. A baseline/status quo scenario which showed the conditions as they were on the ground without any intervention was incorporated in the choice set as an alternative. This allowed those respondents who were satisfied with the status quo to select neither of the proposed alternatives without being forced to change which, according to Hanley et al., (2001) and Ruto et al. (2009), helps the results obtained in the analysis to be more consistent with demand theory. It is only the attributes presented in the choice set that were considered in the choices by the respondents during the survey. They were asked to consider each choice set independently of the other. An experimental design software NGENE was used to generate the design (ChoiceMetrics, 2009).

Table 2: A choice set used in the DCE design

\begin{tabular}{|c|c|c|c|}
\hline $\begin{array}{l}\text { Grazing management } \\
\text { attributes }\end{array}$ & Alternative A & Alternative B & Alternative $\mathrm{C}$ \\
\hline $\begin{array}{l}\text { Construction of water } \\
\text { pans }\end{array}$ & Yes & No & No addition \\
\hline $\begin{array}{l}\text { Biomass threshold to stop } \\
\text { grazing }\end{array}$ & High & Medium & No threshold \\
\hline $\begin{array}{l}\text { Grazing ban in the wet } \\
\text { season }\end{array}$ & Six months & Two months & No grazing ban \\
\hline Forage yield & Lower yield & Medium yield & $\begin{array}{l}\text { No extra forage } \\
\text { produced }\end{array}$ \\
\hline Water availability & $\begin{array}{l}\text { Less water storage } \\
\text { capacity }\end{array}$ & $\begin{array}{l}\text { More water storage } \\
\text { capacity }\end{array}$ & No influence \\
\hline $\begin{array}{l}\text { Annual membership fee } \\
(\text { Ksh) }\end{array}$ & 600 & 900 & $\begin{array}{l}\text { No membership } \\
\text { fee }\end{array}$ \\
\hline $\begin{array}{l}\text { Which alternative do you } \\
\text { prefer? }\end{array}$ & & & \\
\hline
\end{tabular}

Source: Authors compilation based on FGDs

Adequate information was provided to enable respondents to understand the DCE exercise and be able to make independent and reliable choices in each situation based on their preferences. Each respondent was presented with a series of choice sets, randomly chosen from one of the six blocks of choice sets from the DCE design, and asked to choose the most preferred option in each case. 


\section{Data collection}

Multistage sampling procedure was used to determine the sampling frame in this study. Three sub-counties namely; Bura, Galole and Garsen inhabited by the agro-pastoralists and the nomadic pastoralists were purposively selected in the first stage of sampling. The second stage involved a systematic random sampling to select five locations from each sub-county giving a total of 15 locations from which sampling was done. This procedure was repeated in the third stage by narrowing down to two smaller administrative units (sub-locations) within each location using the systematic random sampling technique giving a total of 30 sub-locations.

A formula by Orme (1998) shown in equation 1 was used to compute the appropriate sample size for the study, taking into consideration the projected number of households of the selected sublocations. The adoption of this formula was informed by the desire to draw a representative sample from the target population and also to minimize sampling error and bias.

$N=500 \times\left(\frac{L}{J X T}\right)$

Where $\mathrm{N}$ is the sample size; $\mathrm{L}$ is the largest number of levels for any of the attributes, $\mathrm{J}$ is the number of choice alternatives; and $\mathrm{T}$ is the number of choice situations in the design. In this study where $\mathrm{L}=3, \mathrm{~J}=3$ and $\mathrm{T}=5$, the sample size was 100 respondents per Sub-county. Given the three sub-counties the total sample size was 300 respondents $(100 * 3$ sites). Data was collected through household surveys involving face-to-face interviews.

\section{Data analysis}

Each respondent was presented with a series of $M=4$ choices. In each choice set, a respondent faced a choice between $\mathrm{J}=2$ alternatives of grazing management plus a status quo. In each scenario (choice set), respondents were asked to choose between two grazing management alternatives allowing for a status quo. The status quo represented the respondent's current feasible choice set. This is important in interpreting the results in standard welfare economic terms (Hanley et al., 2001). Therefore, the attributes of alternative $i$ in choice situation $t$ faced by

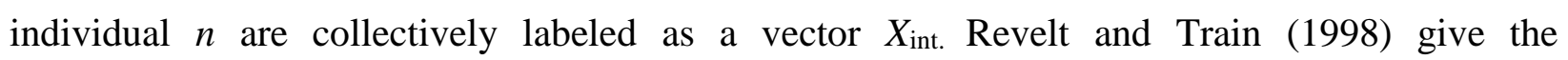
specification of the utility derived by person $n$ from alternative $j$ as follows: 


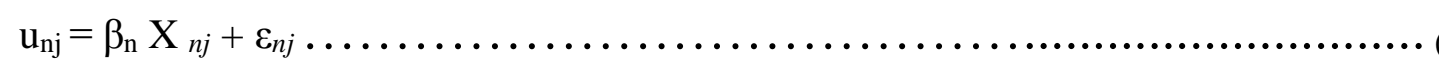

Where $X_{n j}$ are the observed variables that relate to the alternative and the decision maker, $\beta_{n}$, a vector of coefficients of these variables for person $n$ representing that person's tastes and $\varepsilon_{n j}$ is a random term that is iid extreme value (for simplicity, the subscript $\mathrm{t}$ for choice situation is suppressed). The coefficients vary over decision makers in the population with density $f\left(\beta_{n} / \theta\right)$. This density is a function of parameters $\theta$ that represent the mean and covariance of the $\beta$ 's in the population.

The value of $\beta_{n}$ and $\varepsilon_{n j}$ are only known to the decision maker for all $j$ alternatives and chooses alternative $i$ if and only if $U_{n i}>U_{n j} \square_{j} \neq i$. The probability that individual $n$ chooses alternative $i$ conditional on $\beta_{n}$, is given by the standard Multinomial Logit Model (MNL) as follows:

$$
L_{n i}\left(\beta_{n}\right)=\frac{e^{\beta} n^{X}{ }_{n i}}{\sum_{j} e^{\beta}{ }^{X_{n j}}}
$$

Let $i(n)$ denote the alternative chosen by individual $n$ in choice situation $t$. The probability of individual $n$ 's observed sequence of choices (conditional on $\beta_{n}$ ) is the product of the MNL with the assumption that the individual tastes, $\beta_{n}$, do not vary over choice situations in repeated choice tasks (although are assumed heterogeneous over individuals):

$$
G_{n}\left(\beta_{n}\right)=\Pi L_{n i}\left(\beta_{n}\right)
$$

Thus, the choice probability follows the expression:

$$
\mathrm{P}_{\mathrm{n}}(\theta)=\int G_{n}\left(\beta_{n}\right) f\left(\beta_{\mathrm{n}} / \theta\right) \mathrm{d} \beta
$$

The expression in equation (5) above has two sets of parameters. The $\beta_{n}$ is a vector of parameters that are specific to individual $n$ (representing individual tastes, which vary between respondents) and $\theta$ are parameters that describe the distribution of the individual specific estimates

The main objective of random parameter logit (RPL) is to specify the function $\mathrm{f}\left(\beta_{\mathrm{n}} / \theta\right)$ and estimate the parameter $\theta$. The estimation of the parameter $\theta$ is done through simulation of the 
choice probability. This is attributed to the fact that the integral equation cannot be computed analytically due to its mathematical closed form (Train, 2003).

The log-likelihood function is specified as:

$L L(\theta)=\sum \mathrm{n} \operatorname{Ln} \mathrm{P}_{\mathrm{n}}(\theta)$

The $P_{n}(\theta)$ is approximated by a summation over randomly chosen values of $\beta_{n}$. For a selected value of parameter $\theta$, a value of $\beta_{n}$ is drawn from its distribution and $G_{n}\left(\beta_{n}\right)$ representing the product of the standard MNL, is computed. Repeated calculations are done for several draws and the average of $G_{n}\left(\beta_{n}\right)$ is considered as the approximate choice probability.

The average is the simulated probability given by:

$$
\operatorname{SP}_{\mathrm{ni}}(\theta)=\frac{1}{R} \sum_{r=1}^{R} G n\left(\beta_{n}^{r}\right)
$$

Where $\mathrm{R}$ is the number of draws and $\mathrm{S} P_{n i}(\theta)$ is unbiased estimator of $P_{n i}(\theta)$ by construction.

The $P_{n i}(\theta)$ is twice differentiable in the parameter $\theta$ and variable $x$, which facilitates numerical search for the maximum likelihood function and the calculation of elasticities. Then, the simulated probabilities are inserted into the log-likelihood function to give a simulated loglikelihood $(S L L)$ function given as

$$
\operatorname{SLL}(\theta)=\sum_{n} \ln \left(\mathrm{Sp}_{n}(\theta)\right)
$$

The estimated parameters are those that maximize $S L L(h)$. Trade-offs between grazing management attributes and money, i.e. the marginal willingness to pay (WTP), is computed as (Hanemann, 1984):

$$
W T P=-1 \times\left(\frac{\beta_{k}}{\beta_{p}}\right)
$$

Where $\beta_{\mathrm{k}}$ is the estimated coefficient for an attribute level in the choice set and $\beta \mathrm{p}$ is the marginal utility of income given by the coefficient of the farmer's membership fee (cost attribute). The marginal WTP (implicit price) for a discrete change in an attribute provides a measure of the relative importance that respondents attach to attributes. 
The results were derived from the analysis of the choices made by the respondents on the grazing profiles, which formed the dependent variable and the attributes described in Table 3 as the independent variables.

Table 3 Description of variables used in the choice analysis

\begin{tabular}{|c|c|}
\hline Variable & Description \\
\hline WATERPAN & $\begin{array}{l}\text { Construction of additional water pans in the wet season grazing areas } \\
(1=\text { Yes, } 0=\text { Otherwise) }\end{array}$ \\
\hline BIOTHRESH & $\begin{array}{l}\text { The minimum amount of forage below which grazing is restricted to allow } \\
\text { grazed pasture to regenerate before grazing (Low, medium, High threshold) }\end{array}$ \\
\hline GRAZBAN & $\begin{array}{l}\text { Grazing ban near permanent water points during the peak of the wet season } \\
\text { to reserve pasture for dry season grazing ( } 1=\text { Six months, } 0=\text { two months })\end{array}$ \\
\hline BIOHIGH & High amount of forage yield ( $1=$ Yes $0=$ Otherwise $)$ \\
\hline BIOMED & yield $(1=$ Yes $0=$ Otherwise $)$ \\
\hline MOREWATE & $\begin{array}{l}\text { More water available in the water-pans and more infiltration into the soil } \\
(1=\text { Yes } 0=\text { Otherwise })\end{array}$ \\
\hline COST & Annual fee paid for using grazing areas (KSh. 600, KSh. 720, KSh. 900) \\
\hline
\end{tabular}

\section{RESULTS}

\section{Random parameter estimates for grazing management attributes}

Table 4 presents the maximum likelihood estimates for the RPL model for grazing management practices. The utility parameters for all attributes were entered as random variables assuming a normal distribution, except the cost attribute which was specified as fixed so as to facilitate estimation of the distribution of WTP, by eliminating the risk of obtaining extreme negative and positive trade-off values (Revelt and Train, 1998).

The results of the RPL model had a log likelihood function of -160.04 and a pseudo-R2 of 0.46. According to Louviere et al. (2000), values of R2 between 0.2 and 0.4 are considered to be indicative of extremely good model fit equivalent to the range of 0.7 to 0.9 found in linear functions such as the stated choice ordinary least squares regression applications. A log likelihood ratio-test confirms that the RPL model provided a better model fit to the data compared to the conditional logit model. The results of the model in table 4 indicate that all the mean coefficients of the attributes investigated are statistically significant $(\chi 2=2316,15 \mathrm{df}, \mathrm{p}<$ $0.00)$. The parameter estimate for annual membership fee was significant $(P<0.01)$ with the 
negative sign, which permits computation of trade-offs between each attribute and money. This implies that the community members were more likely to choose the profile or participate in the management of the grazing practices that have more benefits to them at a lower cost.

Table 4 Random parameter estimates for the improved grazing management attributes

\begin{tabular}{|c|c|c|c|c|}
\hline \multirow{2}{*}{$\begin{array}{l}\text { Choice } \\
\text { WATERPAN }\end{array}$} & \multirow{2}{*}{$\begin{array}{l}\text { Coefficient } \\
4.70 * * *\end{array}$} & \multirow{2}{*}{$\begin{array}{l}\text { Std. error } \\
1.01\end{array}$} & \multicolumn{2}{|c|}{$95 \%$ confidence interval } \\
\hline & & & 1.20 & 8.26 \\
\hline LOWBIOTH & $-3.14 * *$ & 1.56 & -8.15 & -.073 \\
\hline MEDBIOTH & $.4780 *$ & 3.58 & -6.53 & 7.49 \\
\hline GRAZBAN & $2.89 * *$ & 1.37 & 5.62 & 6.13 \\
\hline BIOHIGH & $10.57 * * *$ & 2.86 & 3.97 & 15.18 \\
\hline BIOMED & $9.58 *$ & 3.07 & 4.3 & 16.37 \\
\hline MOREWATE & $18.77 * * *$ & 5.79 & 7.04 & 29.75 \\
\hline COST & $-.00627 * * *$ & .00214 & -.01047 & -.00207 \\
\hline \multicolumn{5}{|c|}{ Standard deviations of parameter distributions } \\
\hline WATERPAN & $13.98 * *$ & 5.57 & 3.06 & 24.89 \\
\hline LOWBIOTH & $5.83 * *$ & 2.31 & 1.29 & 10.36 \\
\hline MEDBIOTH & $3.89 *$ & 2.42 & -.85681 & 8.65079 \\
\hline GRAZBAN & $8.16 * * *$ & 2.78 & 2.70 & 13.63 \\
\hline BIOHIGH & $0.01307 * * *$ & 3.01 & -5.89 & 5.92 \\
\hline BIOMED & $3.896^{*}$ & 2.425 & -0.865 & 8.65 \\
\hline MOREWATE & $7.02 * *$ & 2.95 & 1.24 & 12.81 \\
\hline Log-likelihood & -160.47 & & & \\
\hline Pseudo-R ${ }^{2}$ & 0.4651 & & & \\
\hline $\mathrm{N}$ respondents & 300 & & & \\
\hline $\mathrm{N}$ choices & 1200 & & & \\
\hline
\end{tabular}

\section{Statistical significance levels: $* * * 1 \%, * * 5 \%$ and $* 10 \%$ respectively}

The coefficients in table 4 show that the parameter estimate for more water levels is of greater magnitude than the rest of the parameter estimates for all the other attributes followed closely by the high biomass yield. The model therefore predicts a higher probability of respondents selecting a profile with grazing management practices that will ensure more water storage 
capacity for the community as well as the biomass yield that will be able to sustain their livestock. All the random parameters estimates are strongly significant indicating that the means of this parameter estimates are statistically different from zero. Since this are random parameters, the results suggest the existence of heterogeneity in the parameter estimates that may be different from the sample population mean of the parameter estimates of these attributes. All the attribute coefficients have highly significant standard deviations, implying that there are, indeed, heterogeneous preferences for these attributes. The estimated means and standard deviations of the normally distributed coefficients provide information on the probability distribution of the population according to the proportion that places a positive value on a particular attribute and the proportion that places a negative value on it (Train, 2003) as shown in Table 5.

Table 5: Preference shares of grazing management attributes

\begin{tabular}{lcccc}
\hline Attribute & Mean & Std. Dev. & Negative share (\%) & Positive share (\%) \\
\hline WATERPAN & 4.70 & 13.980 & 36.84 & 63.16 \\
LOWBIOTH & -3.14 & 5.830 & 70.49 & 29.51 \\
MEDBIOTH & 0.48 & 3.89 & 45.11 & 54.89 \\
GRAZBAN & 2.89 & 8.160 & 36.16 & 63.84 \\
BIOHIGH & 10.57 & 0.013 & 0.00 & 100.00 \\
BIOMED & 9.58 & 3.896 & 0.70 & 99.30 \\
MOREWATE & 18.77 & 7.020 & 0.37 & 99.63 \\
\hline
\end{tabular}

Majority of the respondents place a positive value on high biomass (100\%) production and availability of more water (99.63\%). However, $70.49 \%$ place a negative value on low biomass threshold to stop grazing which was used as a proxy for high grazing pressure that is likely to result in overgrazing. A proportion of $63.16 \%$ of the respondents would prefer addition of waterpans while $63.84 \%$ place a positive value on the grazing ban around the water points in wet season to reserve them as dry season grazing areas.

\section{Economic values of the attributes}

Table 6 presents estimates of willingness to pay (WTP) for the respective attributes derived from the model. The mean welfare estimates for the random parameters were obtained by simulations, drawn from 10,000 replications in R-software based on the RPL model results shown in Table 4. 
Table 6: Economic Values attached to the grazing management attributes

\begin{tabular}{c|cccc}
\hline Attributes & WTP $($ KSh $)$ & Std error & 95\% confidence interval \\
\hline WATERPAN & $432.56^{* * *}$ & 93.97 & 248.37 & 616.76 \\
LOWBIOTH & $-376.15^{* * *}$ & 110.71 & -593.15 & -159.15 \\
MEDBIOTH & $117.06^{*}$ & 357.72 & -584.05 & 818.17 \\
GRAZBAN & $256.95^{* *}$ & 134.53 & 220.68 & 276.68 \\
BIOHIGH & $1527.83^{* * *}$ & 263.01 & 1248.66 & 2494.98 \\
BIOMED & $1439.25^{* * *}$ & 247.65 & 953.87 & 1921.63 \\
MOREWATER & $2088.28^{* * *}$ & 369.35 & 1364.36 & 2812.21 \\
\hline
\end{tabular}

Statistical significance levels: $1 \% ; * * * 5 \% * *$ and $10 \% *$ respectively

The estimated pastoral communities' marginal WTP for water and biomass were the highest in the ranking of the attributes. The results indicate that each household is willing to pay Ksh. 2,088 and 1,528 annually for management of water and high biomass yield respectively. Further, results indicate that each pastoral household would be willing to accept (WTA) compensation of approximately Ksh. 376 annually from a welfare loss if a low grazing threshold is tolerated in the grazing management. Respectively, the derived WTP for addition of water pans and dry season grazing reserves was Ksh. Ksh. 432 and 256 annually.

\section{Discussion}

\section{Preferences for grazing management practices}

Tana River County is considered a water-scarce county in Kenya with most of the area regularly experiencing extreme water shortage during periodic dry spells. Rapid population growth and inefficient use of resources increases the deficit between available water supplies and the needs of people. The entire county is drought prone and the vulnerability of the population to drought is high with majority of the people in the county living in very dry areas especially the Orma and Wardey Community. This explains why the parameter estimates for the addition of water pans are positive with strong statistical significance. Pastoral communities derive a positive utility 
from the construction of water pans in the wet season grazing areas which are areas far from the permanent water points. Rapid runoff during the rainy season frequently results in a high proportion of water in the county not being utilized, or even becoming destructive. Water scarcity is therefore the biggest constraint to sustainable livelihoods of these communities who depend largely on livestock as their main source of livelihood. Harvesting rainwater where and when it falls in the water pans presents opportunities to address both water scarcity and soil degradation at a local level. Addition of more water pans will therefore benefit the community in addressing the challenges of water shortages hence higher proportion of the population place a positive preference on the construction of water pans.

The pastoral communities recognize the fact that regulation of grazing by designating wet and dry season grazing reserves is important as an adaptation strategy to the frequent dry spells. This is shown by the positive and significant parameter attribute for grazing ban near permanent water points during the peak of the wet season to reserve pasture for dry season grazing and opening of migratory corridors. This attribute was intended to reduce pressure around the water points during the wet season. During the wet season, there is usually plenty of pasture enough for the animals across the area. The animals can therefore graze at a distance further from the water points and reserve areas near the water points for dry season use. Reserving these areas when the distant areas have enough pasture to sustain the animals is therefore vital in ensuring that in the dry spells the animals come near the water points and find some pasture. Migratory corridors are to be designated to allow reciprocal access of the dry season grazing reserves to avoid conflicts with the settled agro-pastoralists in the area. A positive utility can be derived from this attribute when there is a strong traditional governance system that can ensure sustainable management of the grazing areas with equitable benefits for all. This is because the community headmen can be held accountable for their decisions and actions with regards to governance of these areas.

Much of the land in the study area is governed as commons with a set of rules and regulations, created and enforced by the traditional council of leaders. This was evident in preservation of watering points in some areas such as 'Wayu' area where proper use and management is guided by traditional leaders where there were sanctions and penalties in form of money or in kind (usually animals) for violations of community bylaws. Leveraging such institutions will greatly help in ensuring the communities have enough pasture near the water points in the dry season grazing reserves. As noted by Robinson and Berkes, (2011), traditional governance systems that 
are well facilitated, strengthened, and properly linked with other governance structures ensure proper management of the natural resources. When communal governance structures are strong they are normally able to amicably deal with resource use, conflict, and management of common resources such as water pans and grazing reserves (Robinson and Makupa, 2015). Therefore, supporting effective management institutions for water and pasture resources in Tana River County, would enable pastoral communities to derive a significant utility from the dry season grazing reserves accessed through migratory corridors.

The negative sign for the parameter estimate for low biomass threshold shows that the pastoralists derive a negative utility from a very low threshold to stop grazing with very high proportion of the respondents placing a negative value on it. A low threshold means high grazing pressure, in this regard; pastoralists are to ensure that grazing livestock assert impact on the pasture and soil for the shortest time possible and allow ample time for the grazed pasture to regenerate as the grazing animals are moved from one place to another without affecting the regrowth of the defoliated forage. A very low threshold is likely to affect the regrowth of biomass leading to overgrazing. The pastoral communities know that keeping animals in one area for a continued period of time affects the reestablishment of the defoliated pasture. This would lead to low biomass yield in the grazing sites when individual plants are subjected to multiple, severe defoliations without sufficient physiological recovery time. High frequency of livestock grazing invariably leads to a decline in the plant's productivity, root biomass and vigor (Kamau, 2004), particularly in species that are less tolerant to high grazing intensities (Metera et al., 2010). This in turn results in less recruitment and survival of preferred plants due to competition from less preferred plant species (Kioko et al., 2012) leading to colonization by highly competitive and tolerant plant species (Sternberg et al., 2000).

The ability of plants to replace tissues lost through grazing and withstand continued defoliation is a function of the rate at which stored carbohydrates are utilized during the dormant or slowgrowing season and subsequently replenished during rapid regrowth period (Adler, 2001). This above ground plant growth dynamic is transmitted to the roots as root growth declines when plant shoots are heavily defoliated because most of the carbohydrate reserves are mobilized and the leaf surface, which has the photosynthetic capacity, is limited after being grazed upon (Holechek et al., 2001). Therefore, management practices must ensure a proper grazing threshold 
to avoid degradation. The pastoral community would hence not prefer a grazing practice that would likely lead to degradation of the grazing fields hence the observed negative utility.

More biomass yield and water levels are the outputs for a good grazing management practice. Having more water points, preventing degradation and overgrazing and preserving dry season grazing area will have a positive effect on biomass yield and water availability. This will benefit the community and provide pasture and water across the seasons. The parameter estimates of both water and forage are positive and strongly significant which means that pastoral communities derive a huge positive utility from both biomass and water. Drylands are predominantly used for livestock production, mainly through pastoralism. Movement of livestock herds is a central component of land management (Galvin, 2009). However, in the study sites, traditional mobility within the pastoralist system of the study sites has been compromised by declining access to water and forage resources. This undermines the ability of the communities to cope with the challenges of a complex and dynamic dry land system. The associated natural pastures are experiencing rapid degradation, thus reducing their contribution to livestock feed. Forage and water are therefore of significant value to pastoral communities hence positive utility.

\section{Economic values of grazing management attributes}

The estimated pastoral communities' marginal WTP for water and biomass were the highest in the ranking of the attributes which show that pastoral communities obtain a high welfare benefit from adequate water and forage for their livestock. Economic value of any good or service is measured in terms of what consumers are willing to pay for the commodity, less what it costs to supply the commodity (Westernberg, 2016). The high marginal willingness to pay for water and biomass therefore show the great economic value attached to them since for environmental goods and services such as rangeland ecosystems, the costs of supply are almost zero, so the consumers' willingness to pay for an environmental resource is usually considered the net value of the resource (Favretto et al., 2016; Kelemen et al., 2014). The basic premise is that ecosystem services arise, either intentionally or unintentionally, from the conservation practice and can have either a positive or a negative value (Mukama, 2010; Lambert, 2003).The scarcity of water, which seems to be a recurrent problem in Tana River County, was reported to force people to use similar water sources for both livestock and human consumption regardless of poor quality. As a 
result, milk yield differs significantly between dry and wet seasons. Fluctuations in milk yield, exhibited in higher milk production in wet season as compared to dry season were directly related to scarcity of forage and water resources coupled with energy expended in searching for forage resources. Thornton and Herrero (2010) reported that poor feed quality leads to poor rangeland productivity in terms of meat and milk production. This explains for the high economic values attached to forage and water.

The willingness to accept (WTA) compensation from a welfare loss if a low grazing threshold is tolerated in the grazing management can be attributed to the negative utility of overgrazing. A low threshold to stop grazing would allow animals to over utilize pasture in a given grazing site for a long period of time which is detrimental to the survival and production of the plants (Steffens et al., 2008). Proper utilization increases forage quality by creating environmental conditions that deter the survival of invasive weed species, while favoring recruitment and survival of palatable forage/browse species (Kinyua et al., 2009).

Oba et al. (2001) observed that when an area is severely utilized to the extent that it does not allow regrowth after defoliation, the incidences of undesirable forage species increase at the expense of more palatable forage species which results in an economic loss. Herbivores therefore essentially affects the composition and productivity of plants through change of plant nativity, recruitment, and mortality (Adler et al., 2005) and this may cause changes in community structure and function (Fortin et al., 2003). An ecosystem may be relatively stable and resistant to changes produced by grazing, up to a certain threshold beyond which further changes are rapidly accentuated by stochastic abiotic factors such as rainfall. These accounts for the negative utility derived from the low threshold a proxy of high grazing pressure and thus willingness to accept compensation due to overgrazing. As indicated by Fraser (2003), given alternative investment opportunities, pastoralists would express low preference for compensation programmes that they might consider being less cost-effective in the use of existing resources. Pastoralists would therefore prefer to invest more on enterprises that they perceive to offer high output at lower cost.

\section{Conclusion}

The results of this study show that pastoralists would prefer to have a grazing management system in which: there are enough water pans to harvest and store water; there is a dry season 
grazing reserve; and overgrazing is limited to avoid degrading the grazing fields and one with enough forage yield and water for the animals. The design of the improved grazing management practice should therefore include these features to enhance its acceptability. Results also show that there is heterogeneity in the preferences for the attributes of improved grazing management system. Because of their relatively high dependence on livestock for income, pastoralists are willing to pay more in order to have enough water and pasture for their animals. Therefore, to improve resilience to droughts and to enhance livelihood opportunities, investments on water provision and pasture development are essential, as a strategy to promote better use of land, especially by pastoralists. Traditional governance systems must be facilitated, strengthened, and properly linked with other governance structures in order to ensure proper management of the natural resources. This will enable the pastoral communities to derive greater utility from management practices that allow reciprocal access of pasture and water across the wet and dry seasons.

\section{References}

Adler P.B., Raff D.A. and Lauenroth W.K. (2001). The effect of grazing on the spatial heterogeneity of vegetation, Oecologia 128: 465-479

Bergman C.M., Fryxell J.M., Gates C.C. and Fortin D. (2001). Ungulate foraging strategies: energy maximizing or time minimizing? Journal of Animal Ecology 70: 289-300.

Bilotta, G.S., Brazier, R.E., Haygarth, P.M., (2007). The impacts of grazing animals on the quality of soils, vegetation, and surface waters in intensively managed grasslands. Advances in Agronomy 94, 237-279. biodiversity of grasslands. Animal Science 81, 193-198

Costanza, R., d'Arge, R., De Groot, R., Farber, S., Grasso, M., Hannon, B. \& Raskin, R. G. (2016). The Value of the World's Ecosystem Services and Natural Capital (1997) The Globalization and Environment Reader, 117 
De Jode, H. (2009).The future of livestock production in Africa's drylands. IIED and SOS Sahel UK ISBN 978-1-84369-752-7 Eastern Ethiopia: A case study conducted in the southern Afar Region in Mbeere District, Kenya. LUCID Working Paper Series No. 36

FAO. (2009). Review of evidence on drylands pastoral systems and climate change: Implications and opportunities for mitigation and adaptation. Edited by C. Neely, S. Bunning and A. Wilkes; Land and Water Discussion Paper 8, ISSN 1729-0554

Favretto, N., Luedeling, E., Stringer, L. C., \& Dougill, A. J. (2016). Valuing Ecosystem Services in Semi-arid Rangelands through Stochastic Simulation. Land Degradation \& Development

Fortin D., Fryxell J.M., O’Brodovich L. and Frandsen D. (2003). Foraging ecology of bison at the landscape and plant community levels: the applicability of energy maximization principles. Oecologia 134: 219-227

Fuhlendorf, S. D., \& Engle, D. M. (2001). Restoring Heterogeneity on Rangelands: Ecosystem Management Based on Evolutionary Grazing Patterns: We propose a paradigm that enhances heterogeneity instead of homogeneity to promote biological diversity and wildlife habitat on rangelands grazed by livestock. BioScience, 51(8), 625-632.

Galvin, K. A. (2009). Transitions: Pastoralists Living with Change. Pages 185-198 Annual Review of Anthropology

Hanley, N., Mourato, S., \& Wright, R. E. (2001). Choice modelling approaches: a superior alternative for environmental valuatioin?. Journal of economic surveys, 15(3), 435-462.

Hanley, N., Wright, R. E., \& Alvarez-Farizo, B. (2006). Estimating the economic value of improvements in river ecology using choice experiments: an application to the water framework directive. Journal of environmental management, 78(2), 183-193.

Holechek, J. L. (2001). Western ranching at the crossroads, Rangelands, 17-21

Kamau, P. 2004. Forage diversity and impact of grazing management on rangeland ecosystems in Mbeere District, Kenya. LUCID Working Paper Series No. 36 
Kassahun, A., Snyman, H. A., \& Smit, G. N. (2008). Impact of rangeland degradation on the pastoral production systems, livelihoods and perceptions of the Somali pastoralists in Eastern Ethiopia Journal of Arid Environments, 72 (7), 1265-1281.

Kelemen, E., García-Llorente, M., Pataki, G., Martín-López, B., \& Gómez-Baggethun, E. (2014). Non-monetary techniques for the valuation of ecosystem services. OpenNESS Reference Book. EC FP7 Grant Agreement, (308428).

Kgosikoma OE (2011). Understanding the savanna dynamics in relation to rangeland management systems and environmental conditions in semi-arid Botswana $\mathrm{PhD}$ thesis Univesity of Edinburgh

Kioko, J., Kiringe, J. W. \& Seno, S. O. (2012). Impacts of livestock grazing on savanna grassland in Kenya, Journal of Arid Land, 4 (1), 29-35.

Lancaster, K.G. 1966. "A New Approach to Consumer Theory." Journal of Political Economy, 74, 132-157.

Lund, H. G. (2007). Accounting for the World's Rangelands, Rangelands, 29(1), 3-10.

Metera, Ewa. (2010). Grazing as a tool to maintain the biodiversity of grassland-a review." Animal Science Papers and Reports 28.4: 315-334.

Mortimore, M. Anderson, S., Cotula, L., Davies, J., Faccer, K., Hesse, C., Morton, J., Nyangena, W., Skinner, J. and Wolfangel, C. (2009). Dryland Opportunities: A new paradigm for people, ecosystems and development, IUCN, Gland, Switzerland; IIED, London, UK and UNDP/DDC, Nairobi, Kenya. ISBN: 978-2-8317-11836

Mwangi, E. and Dohrn, S. (2006). Biting the Bullet: How to Secure Access to Drylands Resources for Multiple Users CAPRi Working Paper no. 47 International Food Policy Research Institute, N.W. Washington, D.C. U.S.A

Oba, G, Vestaas, O, R. and Stenseth, N.C. (2001). Relationships between biomass and plant species richness in arid-zone grazing lands Journal of Applied Ecology, 38: 836-846

Orme, B. (1998). Sample size issues for conjoint analysis studies. Sawthooth Software Research paper Series. Squim, WA, USA: Sawthooth Software Inc. 
Otieno, D. J. (2011). Economic analysis of beef cattle farmers' technical efficiency and willingness to comply with disease free zones in Kenya.

Reid, R. S., Galvin, K. A., \& Kruska, R. S. (2008) Global significance of extensive grazing lands and pastoral societies: an introduction. In Fragmentation in semi-arid and arid landscapes (pp. 1-24) Springer Netherlands

Revelt, D., \& Train, K. (1998). Mixed logit with repeated choices: households' choices of appliance efficiency level. Review of economics and statistics, 80(4), 647-657.

Robinson, L. W., \& Berkes, F. (2011). Multi-level participation for building adaptive capacity: Formal agency-community interactions in northern Kenya. Global Environmental Change, 21(4), 1185-1194.

Robinson, Lance W. and Enock Makupa. 2015. Using Analysis of Governance to Unpack Community-Based Conservation: A Case Study from Tanzania. Environmental Management, v. 56(5): 1214-1227.

Rose, J. M. and Bliemer, M. C. J. (2009), 'Constructing efficient stated choice experimental designs', Transport Reviews, 29(5):587-617.

Ruto, E., \& Garrod, G. (2009). Investigating farmers' preferences for the design of agrienvironment schemes: a choice experiment approach. Journal of Environmental Planning and Management, 52(5), 631-647.

Ruto, E., Garrod, G., \& Scarpa, R. (2008). Valuing animal genetic resources: a choice modeling application to indigenous cattle in Kenya. Agricultural Economics, 38(1), 89-98.

Scarpa, R., \& Rose, J. M. (2008). Design efficiency for non-market valuation with choice modelling: how to measure it, what to report and why. Australian journal of agricultural and resource economics, 52(3), 253-282.

Scarpa, R., Ruto, E. S., Kristjanson, P., Radeny, M., Drucker, A. G., \& Rege, J. E. (2003). Valuing indigenous cattle breeds in Kenya: an empirical comparison of stated and revealed preference value estimates. Ecological Economics, 45(3), 409-426.

Steffens, M., Kölbl, A., UweTotsche, K., Kögel-Knabner, I. (2008). Grazing effects on soil chemical and physical properties in a semiarid steppe of Inner Mongolia (P.R. China) Geoderma 143, 63-72 
Sternberg M, Gutman M, Perevolotsky A, Ungar ED, Kigel J (2000). Vegetation response to grazing management in a Mediterranean herbaceous community: a functional group approach. Journal of Applied Ecology.37:224-237

Thornton PK, 2010. Livestock Production: Recent trends, future prospects. Philosophical Transactions of the Royal Society Series B 365, 2853-2867

Thornton, P. K., \& Herrero, M. (2010). Potential for reduced methane and carbon dioxide emissions from livestock and pasture management in the tropics. Proceedings of the National Academy of Sciences, 107(46), 19667-19672.

Train, K. (2003). Discrete choice methods with simulation. Cambridge university press. 